\title{
Differences in urinary tract infections in male and female spinal cord injury patients on intermittent catheterization
}

\author{
C J Bennett ${ }^{1}$, M N Young ${ }^{2}$ and H Darrington ${ }^{3}$ \\ ${ }^{1}$ Associate Professor of Urology, USC School of Medicine, University of Southern California, Los Angeles CA \\ and Chief, Urology, Rancho Los Amigos Medical Center, Downey, CA; ${ }^{2}$ Urological Nursing Services, \\ Department of Nursing, Rancho Los Amigos Medical Center, Downey, CA, USA
}

\begin{abstract}
Intermittent catheterization has gained wide acceptance for use in hospitalized patients following spinal cord injury. Most studies evaluating this procedure, however, look only at the infection rate in the male SCI population. In this study the rate and type of infection encountered in the male and female SCI population were evaluated in an inpatient hospital environment. Fifty four patients who were undergoing intermittent catheterization with the MMG/O'Neil catheter system were evaluated. All patients were similar with regard to level of injury and bladder management. There were 45 males and nine females in our study group $(n=54)$. A total of 10945 catheterizations were performed with 75 infections indentified. The overall infection rate was $0.68 \%$ or one infection for every 146 catheterizations. Of the 45 males there were 58 infections of which $11(18 \%)$ were E. coli. This contrasts with the female population (9) in which there were 17 infections with nine (53\%) being $E$. coli. While a variety of infecting organisms were present in males, females were colonized with either $E$. coli, enterococcus or Klebsiella. While hospital based intermittent catheterization would appear to be associated with an acceptable low incidence of urinary tract infections $(0.68 \%)$, infected females have a higher incidence of E. coli $(53 \%)$ compared to the male population $(18 \%)$. This study also demonstrated that female patients had a significantly higher infection rate than males (nine females with 17 infections compared to 45 males with 58 infections over the same time period). The higher incidence of urinary tract infections in females with $E$. coli perhaps is related to the proximity of bowel/stool contamination.
\end{abstract}

Keywords: intermittent catheterization; urinary tract infections (male/female); urethral colonization; E. coli

\section{Introduction}

As reported by the National Spinal Cord Injury Statistical Center in Birmingham, Alabama, there are approximately 7800 new spinal cord injuries (SCI) a year in the United States. Eighty two percent are male; while $18 \%$ are female. The majority of these patients have complete injuries resulting in neuropathic bladder dysfunction. Intermittent catheterization (IC) has gained acceptance as the preferred method of early neuropathic bladder management since the late 1960s. ${ }^{1-3}$ More recently, Stover et al $^{4}$ reported that there was lack of universal agreement on the most efficacious long term management of the neuropathic bladder and that there was no consensus on the significance of urinary tract infection (UTI) in overall bladder management. Since females represent a minority of spinal injured persons, few studies address their unique concerns. The diagnostic and management principles for females tend to be extrapolated from the

Correspondence: Carol Bennett MD, Department of Urology, Rancho Los Amigos Medical Center, 7601 East Imperial Highway, Downey, CA 90242, USA data on males, a problem noted by the National Institute on Disability and Rehabilitation Research (NIDRR) at a recent conference. It was advised that more research was required with this group. ${ }^{5}$ This study examines the rate and type of UTI in both the inpatient male and female SCI population and evaluates the effectiveness of the MMG/O'Neil (MMGON) catheter, (Medical Marketing Group, Atlanta, Georgia).

\section{Methods}

Fifty four patients who were undergoing IC with the MMGON catheter system were evaluated and data was collected over a 3 month period. All ICs were performed by a specialized team of urology technicians. The average length of time for patients in the study was 6 weeks. The patients were cared for at Rancho Los Amigos Medical Center on the spinal injury unit which consists of six-bed rooms. There were 45 males and nine females in the study. The patients were similar with regard to level of injury and bladder management. The male patients were either on IC, not voiding, not wearing external urinary collection system (EUCS) or 
on IC, voiding reflexly and wearing an EUCS. Female patients were on IC, not voiding, and not wearing padding or on IC, voiding and wearing padding. Patients classified as being on IC, voiding and wearing EUCS or padding were those voiding by reflex or strain but did not empty their bladder adequately and needed to continue IC. The patients who were on IC and not voiding were on a catheterization schedule every 4 to $6 \mathrm{~h}$, while the patients who were voiding were catheterized every 6 to $8 \mathrm{~h}$. The number of patients doing self versus care-giver doing IC in each group was similar (Table 1). UTI in this study was defined as a bacterial colony count greater than 100000 . Urine cultures were obtained by sterile catheterization weekly and UTIs were treated with antibiotics for 10 days according to the sensitivity of the organism.

A new catheter system, the MMGON, was utilized for intermittent catheterization. The catheter is enclosed in a plastic sleeve, is pre-lubricated, and has a urethral introducer tip which protects the catheter from being contaminated by the colonized first $1.5 \mathrm{~cm}$ of the urethra, thus reducing the incidence of UTI. ${ }^{6}$

\section{Results}

A total of 10945 catheterizations were performed with the identifications of 75 infections. The overall infection rate was $0.68 \%$ or one infection in every 146 catheterizations. Of the 45 male patients there were 58 infections of which 15 were Klebsiella, 13 were enterococcus, 11 were E. coli, five were Pseudomonas, three were Enterobacter, two were Staphylococcus, and nine were other organisms. In contrast, in the female population (9) there were 17 infections of which nine were E. coli, four were Klebsiella, three were enterococcus and one Citrobacter. Comparison of the two cohorts, 45 males with 58 infections versus nine females with 17 infections indicate that the two were significantly different, $(P=0.0107)$. In the male population 11 out of 54 infections (18\%) were E. coli compared to the female population in which nine of 17 infections (53\%) were E. coli (Table 2). Comparing the number of $E$. coli infections among males versus females using chi square analysis, females were shown to have a significantly greater proportion of $E$. coli infections, $(P<0.02)$. While multiple infecting organisms were present in males, females were colonized with either E. coli, enterococcus or Klebsiella.

Table 1 Number of patients doing self versus care-giver intermittent catheterisation

\begin{tabular}{llll}
\hline \multicolumn{2}{c}{ Males $(45)$} & \multicolumn{2}{c}{ Females $(9)$} \\
\hline Paraplegic & $27(60 \%)$ & Paraplegic & $4(45 \%)$ \\
Quadriplegic & $18(40 \%)$ & Quadriplegic & $5(55 \%)$ \\
IC only & $31(69 \%)$ & IC only & $7(77 \%)$ \\
IC external or & $14(31 \%)$ & IC external or & $2(23 \%)$ \\
$\quad$ padding & & padding & \\
Self IC & $23(51 \%)$ & Self IC & $4(45 \%)$ \\
Staff IC & $22(49 \%)$ & Staff IC & $5(55 \%)$ \\
\hline
\end{tabular}

Table 2 Urinary tract infection rate in 1094 catheterizations $(0.68 \% \text { or one infection per } 146 \text { catheterizations })^{\mathrm{a}}$

\begin{tabular}{lrll}
\hline \multicolumn{1}{c}{$\begin{array}{c}\text { Males } \\
n=45 \\
\text { Infections } 58\end{array}$} & \multicolumn{2}{c}{$\begin{array}{c}\text { Females } \\
n=9 \\
\text { Infections } 17\end{array}$} \\
\hline Klebsiella & $15(26 \%)$ & E. coli & $9(53 \%)$ \\
Enterococcus & $13(22 \%)$ & Klebsiella & $4(24 \%)$ \\
E. coli & $11(19 \%)$ & Enterococcus & $3(18 \%)$ \\
Pseudomonas & $5(9 \%)$ & Citrobacter & $1(5 \%)$ \\
Enterobacter & $3(5 \%)$ & & \\
Staphlococcus & $2(4 \%)$ & & \\
Other & $9(15 \%)$ & & \\
Males 19\% E. coli & & Females 53\% E. coli ${ }^{\mathrm{b}}$
\end{tabular}

${ }^{\mathrm{a}} P=0.0107 ;{ }^{\mathrm{b}} P<0.02$

\section{Discussion}

A review of the literature notes numerous risk factors for increased UTI in the SCI population. McGuire and Savastano ${ }^{7}$ reported that while one third of patients maintained on long term intermittent catheterization remained free of UTI, the remaining two thirds had chronic or recurring bacteriuria. LLoyd et al ${ }^{8}$ reported that $80 \%$ of patients voiding reflexively had chronic or recurrent bacteriuria. Perkash and Giroux ${ }^{9}$ credit adequate bladder drainage as the most effective method of preventing recurrent symptomatic infections. Lapides ${ }^{10}$ in 1974 evaluated the causes of urine infection in neuropathic bladders and concluded that host resistance was the most important factor in preventing lower urinary tract infection, and that infecting microorganisms play a secondary role. In effect it has been established that most normal human bladders are resistent to infection even when contaminated with gram-negative organisms, so that a change in the bladder mucosa must take place in order for infecting organisms to produce a clinical UTI. He believed maintenance of tissue integrity was essential in deterring bacterial invasion. Tissue integrity can be adversely affected by instrumentation, neoplasm, tuberculosis, calculi, indwelling catheters and the like. Lapides further proposed that an impairment of bladder vascular circulation results in a deterioration in the local tissue immunity provided by structural integrity. Increased intravesical pressure and detrusor overdistention which cause both a loss of tissue immunity and impaired bladder circulation are usually associated with an increased incidence of urinary infection. More recently Hackler ${ }^{11}$ noted that those spinal injured patients with hypocompliant bladders had a $64 \%$ incidence of hydronephrosis. Likewise, Bennett et al ${ }^{12}$ concluded that high pressure detrusor hyperreflexia particularly in the presence of detrusor sphincter dyssynergia may lead to urinary stasis and turbulence in the proximal urethra, thereby increasing the risk of urine infection. Though numerous studies note that IC has lowered the incidence of UTI and reduced the incidence and severity of upper tract and other complications, ${ }^{13-16}$ hospital infection rates for patients on IC 
remain high. Recently, the consensus validation conference sponsored by NIDRR listed the risk factors for UTI in the SCI population as: over-distended bladder, vesicoureteral reflux, high pressure voiding, large post-void residuals, presence of stones in the urinary tract, and outlet obstruction. It was concluded that although the risk of infection is reduced with IC, the risk for UTI still exists. ${ }^{5}$ In hospitalized patients this results in increased morbidity, loss of therapy time for patients, increased length of hospital stay, and increased costs for rehabilitation.

\section{Urethral colonization and UTI}

Colonization of the distal urethra in spinal injured patients is well documented. Hirsh ${ }^{17}$ believed colonization beneath the external catheter and extension into the distal urethra put patients at greater risk for development of UTI when on external catheter and intermittent catheterization. Montgomerie et al ${ }^{18,19}$ and Gilmore et al,,$^{20,21}$ did multiple studies looking at colonization of Pseudomonas and Klebsiella in the perineum and urethra in spinal injured males. These studies looked almost exclusively at male patients and showed considerably more urethral colonization in patients wearing external catheters but did not show a higher incidence of UTI in this group.

Because females represent a minority of spinal injured persons, there are few studies which address their unique concerns. Pearman et al ${ }^{22}$ reported a higher incidence of UTI in his female group, a significant problem in our SCI female population. Our own experience and this data would indicate that not only is the incidence of UTI higher in females, but that the pathogens are different as well. Fowler ${ }^{23}$ reported that $E$. coli are responsible for $75 \%$ of infections in adult women. $\mathrm{He}$ reports that there is convincing evidence that infection in the urine of these women was preceded by colonization of the vaginal and urethral mucosa with the infecting organism. This is in agreement with past studies by Stamey and Sexton ${ }^{24}$ who believed that vaginal colonization preceded urinary tract infections in women. The women represented in these two studies, however, were not SCI women with neuropathic voiding dysfunction.

A review of the literature identified no studies which addressed the issue of fecal contamination and the risk of UTI in spinal injured women. Lara et al ${ }^{25}$ reported in a study of 99 male patients in a Veterans Administration (VA) medical center, nursing home care unit, that the incidence of UTI was $70 \%$ in men with bowel incontinence compared with $25 \%$ in their bowel continent counterparts.

The MMGON catheter was originally developed for female patients in Australia, and has been available in America for 7 years. Since then three preliminary studies have shown a significant reduction in infection rates in spinal injured patients using the MMGON system. Charbonneau-Smith (unpublished abstract) showed that $77.3 \%$ of the control group using a sterile system with a straight catheter had more than one infection per admission compared with $44.4 \%$ of the group using the MMGON. Pang-Wright and Dasalla ${ }^{26}$ also demonstrated a lower incidence of UTI using the MMGON but could not establish a significant difference because of the small size of their sample. Young and Bennett $^{27}$ demonstrated a $30 \%$ reduction in infection rate over a 3 year period using the MMGON system compared with an alternate closed method system in which the catheter also was enclosed in a plastic sleeve, but was not self-lubricated and had no introducer tip. The infection rate in the group (without introducer tip) was $0.91 \%$ or one infection for every 109 catheterizations. Furthermore it was demonstrated that when using the non introducer tip enclosed system, $84 \%$ of the infecting organism in women were $E$. coli (unpublished data).

In this present study using the MMGON catheter system the overall infection rate was low $(0.68 \%)$. Nevertheless, women still maintained a higher infection rate than their male counterparts (nine females with 17 infections compared to 45 males with 58 infections over the same time period and frequency of IC). The incidence of $E$. coli in women, however, was reduced from $84 \%$ to $53 \%$ using the MMGON system.

These findings raise the possibility that the higher incidence of UTI in female patients perhaps is related to the proximity of bowel/stool contamination and linked to the patient's bowel management program. There is a large amount of fecal contamination of the perineum in women who have their bowel program in bed during the initial stages of their rehabilitation. It is intriguing to postulate that women who have their bowel program on the commode would have less contamination of the perineum and thereby reduce their infection rate. Further studies on female patients are necessary to correlate their type of bladder and bowel management programs and the use of incontinence padding with infection rates and infecting organisms. In conclusion, while hospital based IC with the MMGON system would appear to be associated with an acceptably low incidence of UTI $(0.68 \%)$, infected females had a higher incidence of $E$. coli $(53 \%)$ compared to the male population $(18 \%),(p<0.02)$.

\section{References}

1 Guttmann L, Frankel H. The value of intermittent catheterization in the early management of traumatic paraplegia and tetraplegia. Paraplegia 1966; 4: 63-84.

2 Comarr AE. Special considerations of the early management of the paralysed bladder. J Indian Med Assoc 1969; 16: $7235-7240$.

3 Lapides J, Diokno AC, Sibler SJ, Lowe BS. Clean intermittent self catheterization in the treatment of urinary tract disease. J Urol 1972; 107: 458

4 Stover SL, Lloyd LK, Waites KB, Jackson AB. Urinary tract infection in spinal cord injury. Arch Phys Med Rehabil 1989; 70: 47-54.

5 National Institute on Disability and Rehabilitation Research (NIDRR) Consensus Statement: The Prevention and management of urinary tract infections among people with spinal cord injuries. J Am Paraplegia Soc 1992; 15: 194-207.

6 O'Neil AGB, Jenkins DT, Wells JI. A new catheter for the female patient. Aust NZ J Obstet Gynaecol 1982; 22: 151-152. 
7 McGuire EJ, Savastano JA. Longterm followup of spinal cord injury patients managed by intermittent catheterization. J Urol 1983; 129: 775-776.

8 Lloyd LK, Kuhlemier KV, Fine PR, Stover SL. Initial bladder management in spinal cord injury: does it make a differcnce? J Urol 1986; 135: 523-527.

9 Perkash I, Giroux J. Prevention, treatment and management of urinary tract infection in neuropathic bladders. J Am Paraplegia Soc $1985 ; \mathbf{8}$ : 15-17.

10 Lapides J. Neurogenic bladder, principles of treatment. Urol Clin N Am 1974; 1: 81-97.

11 Hackler, RH. A 25 year prospective mortality study in the spinal cord injured patient: Comparison with the long-term living paraplegic. J Urol 1977; 117: 486-488.

12 Bennett JK, Gray M, Green BG, Foote JE: Continent diversion and bladder augmentation in spinal cord injured patients Semin Urol 1992; 10: 121-132.

13 Guttmann L. Disturbances of the bladder and upper urinary tract. In: Spinal Cord Injuries-Comprehensive Management and Research. 2nd edn. Oxford: Blackwell Scientific Publications, 1976, pp 331-457.

14 Maynard FM, Diokno AC. Urinary infection and complications during clean intermittent catheterization following spinal cord injury. J Urol 1984; 132: 943-946.

15 Viera A, Merritt JL, Erickson RP. Renal function in spinal cord injury: A preliminary report. Arch Phys Med Rehabil 1986; 67: 257-258.

16 Hill VB, Davies WE. A swing to intermittent self catheterization as a preferred model of management of the neuropathic bladder for dextrous spinal cord patient. Paraplegia 1988; 26: 405-412.

17 Hirsh DD, Fainstein V, Musher CM. Do condom catheter collecting systems cause urinary tract infection? JAMA 1979;
242: 340-341.

18 Montgomerie JZ, Morrow JW. Long-term Pseudomonas colonization in spinal cord injury patients. Am J Epidemiol 1980; 112: $508-517$.

19 Montgomerie JZ et al. Long-term colonization of spinal cord injury patients with Klebsiella Pneumoniae. J Clin Microbiol 1989; 27: 1613-1616.

20 Gilmore DS et al. Pseudomonas aeruginosa colonization in patients with spinal cord injuries. J Clin Microbiol 1982; 16: 856-860.

21 Gilmore DS, Schick DG, Young MN, Montgomerie JZ. Effect of external urinary collection system on colonization and urinary tract infections with Pseudomonas and Klebsiella in men with spinal cord injury. J Am Paraplegia Soc 1992; 15: 206-208.

22 Pearman JW, Bailey M, Riley LP. Bladder installations of Trisdine compared with catheter introducer for reduction of bacteriuria during intermittent catheterization of patients with acute spinal cord trauma. Br J Urol 1991; 67: 483-490.

23 Fowler JE, Jr. Urinary tract infections in women. Urol Clin $N$ Am 1986; 13: 673-683.

24 Stamey TA, Sexton CC. The role of vaginal colonization with Enterobacteriaceae in recurrent urinary infections. J Urol 1975; 113: 214-217.

25 Lara L, Troop PR, Beadleson-Baird M. The risk of urinary tract infection in bowel incontinent men. $J$ Gerontol Neurosurg 1990; 16: 24-26.

26 Pang-Wright B, Dasalla E. A descriptive study utilizing two different intermittent catheterization techniques in SCI clients in an acute rehab facility, (abstract). American Association of Spinal Cord Injury Nurses, Les Vegas, Nevada, 1990.

27 Young MN, Bennett CJ. The use of a closed intermittent catheter system in hospitalized patients following spinal cord injury (abstract). Arch Phys Med Rehabil 1992; 73 (suppl): 983. 